\title{
Dietary supplementation of micro- encapsulated sodium butyrate in healthy horses: effect on gut histology and immunohistochemistry parameters
}

\author{
W. A. Wambacq ${ }^{1 *}$, D. A. van Doorn ${ }^{2,3}$, P. M. Rovers-Paap ${ }^{4}$, R. Ducatelle ${ }^{5}$, L. Vlaminck ${ }^{6}$, M. Lourenço ${ }^{1,7}$ and M. Hesta ${ }^{1}$
}

\begin{abstract}
Background: As colic and intestinal disorders are a major concern in horses, the aim of the present study was to investigate the effect of dietary supplementation of butyrate, known to have a diverse array of beneficial effects on intestinal health. The effect of micro-encapsulated sodium butyrate supplementation on gut histology and immunohistochemistry parameters was studied in 14 healthy warmblood horses destined for slaughter in two separate periods. Horses were fed a low fiber - high starch diet, designed to induce subsequent starch overflow in the large intestine, aiming to create a mild challenge for large intestinal health. Treatment included supplementation with either micro-encapsulated sodium butyrate (Excential Butycoat ${ }^{\oplus}$, Orffa, Werkendam, the Netherlands) or placebo (containing only coating material). The horses were fed for 20 consecutive days at a dosage of $0.4 \mathrm{~g} / \mathrm{kg}$ BW (body weight). At day 21, the horses were slaughtered and intestinal samples were collected for determination of gut pH, villus length, crypt depth and area \% of CD3+ and CD20+ cells.

Results: Horses on the butyrate supplemented diet had significantly reduced crypt depths in the right dorsal colon compared to placebo-fed horses $(P<0.001)$. However, a treatment $x$ period interaction $(P=0.002)$ was discovered regarding this parameter, which could not be explained by the authors. Further investigation into the number of KI67+ cells in the RDC crypts did not reveal any significant differences between treatments $(P=0.650)$, indicating that the reduction in crypt depth in butyrate-fed horses could not be explained by a significant difference in cellular proliferation. Intestinal pH, villus length and expression of intestinal CD3+ and CD20+ cells were not significantly affected by treatment at any intestinal level.

Conclusions: Our data indicate that supplementation of micro-encapsulated sodium butyrate to the equine diet did not influence gut histology (with the exception of a decrease found in the crypts of the RDC) or immunohistochemistry parameters in healthy horses. Further research is warranted to investigate the impact of butyrate supplementation in horses with intestinal disease.
\end{abstract}

Keywords: Butyrate, Diet, Equine, Histology, Immunohistochemistry

\footnotetext{
* Correspondence: wendy.wambacq@ugent.be

'Laboratory of Animal Nutrition, Department of Nutrition, Genetics and

Ethology, Faculty of Veterinary Medicine, Ghent University, Heidestraat 19,

9820 Merelbeke, Belgium

Full list of author information is available at the end of the article
}

C C The Author(s). 2020 Open Access This article is licensed under a Creative Commons Attribution 4.0 International License, which permits use, sharing, adaptation, distribution and reproduction in any medium or format, as long as you give appropriate credit to the original author(s) and the source, provide a link to the Creative Commons licence, and indicate if changes were made. The images or other third party material in this article are included in the article's Creative Commons licence, unless indicated otherwise in a credit line to the material. If material is not included in the article's Creative Commons licence and your intended use is not permitted by statutory regulation or exceeds the permitted use, you will need to obtain permission directly from the copyright holder. To view a copy of this licence, visit http://creativecommons.org/licenses/by/4.0/ The Creative Commons Public Domain Dedication waiver (http://creativecommons.org/publicdomain/zero/1.0/) applies to the data made available in this article, unless otherwise stated in a credit line to the data. 


\section{Background}

Gastrointestinal health is an important topic in equine practice, as colic remains to this day one of the major causes of death in horses [1]. Feeding high-starch diets to horses is considered in conflict with the natural feed intake behavior but still common in practice [2]. Including high amounts of cereals or concentrate inclusion may result in undigested starch reaching the hindgut, increasing the risk for microbiome dysbiosis and subsequently colic [3]. Colic and intestinal disorders are also known to influence gut wall integrity [4], and can cause alterations such as mucosal degeneration in case of intestinal strangulation [5]. The objective of the current study was to investigate whether a dietary supplement could counteract the potential negative health effects on gut wall dynamics that have been associated with the feeding of high-starch diets. Research in other animal species has shown that increasing the concentration of the short chain fatty acid butyric acid in the intestinal lumen results in a diverse array of beneficial effects on intestinal health [6]. This end-product of microbial fermentation of fiber was previously described as the metabolic fuel of choice for colonocytes, resulting in increased colonocyte differentiation in both in vitro and in vivo studies in rats [7, 8]. In addition, there is evidence that butyric acid has an anti-inflammatory effect
$[9,10]$, can modulate oxidative stress $[11,12]$, increase intestinal blood flow [13], and decrease the proliferation and differentiation of tumor cell lines [8]. Therefore, the aim of the present study was to investigate the effects of dietary supplementation of micro-encapsulated sodium butyrate on gut $\mathrm{pH}$, villus length, crypt depth and CD3 and CD20 expression in healthy adult horses subjected to a high starch diet. This is the first study investigating the effect of sodium butyrate supplementation in the equine species.

\section{Results}

Feed intake, body weight, fecal pH and fecal consistency during supplementation period

Diets were well tolerated and none of the horses showed signs of illness, except for two horses that experienced hyporexia (for one and 3 days, respectively). Feed intake, body weight and fecal parameters are shown in Tables 1 and 2. There was no significant effect of time nor treatment on feed intake in all horses. A significant $(P<$ 0.001) increase in body weight was observed during the course of the study for both groups, without statistical differences between the two dietary groups $(P=0.164)$. An average daily decrease of $0.013 \mathrm{pH}$ units was observed in fecal $\mathrm{pH}$ from placebo-fed horses throughout the study $(P=0.05)$. There was no difference between

Table 1 Feed composition and mean feed intake, bwt, fecal pH and consistency at day 1 and 20

\begin{tabular}{|c|c|c|c|c|}
\hline Component & \multicolumn{2}{|c|}{ Haylage $^{\mathrm{a}}$} & \multicolumn{2}{|c|}{ Concentrate ${ }^{a, b}$} \\
\hline DM, g/kg product & \multicolumn{2}{|l|}{861.6} & \multicolumn{2}{|l|}{895.4} \\
\hline Crude ash, g/kg DM & \multicolumn{2}{|l|}{59.3} & \multicolumn{2}{|l|}{63.0} \\
\hline Crude fiber, g/kg DM & \multicolumn{2}{|l|}{324.1} & \multicolumn{2}{|l|}{50.9} \\
\hline Crude fat, g/kg DM & \multicolumn{2}{|l|}{11.1} & \multicolumn{2}{|l|}{81.3} \\
\hline Crude protein, g/kg DM & \multicolumn{2}{|l|}{80.3} & \multicolumn{2}{|l|}{134.1} \\
\hline Sugar, g/kg DM & \multicolumn{2}{|l|}{137.1} & \multicolumn{2}{|l|}{60.5} \\
\hline Starch, g/kg DM & \multicolumn{2}{|l|}{0.0} & \multicolumn{2}{|l|}{351.2} \\
\hline Component & \multicolumn{2}{|c|}{ Butyrate supplement } & \multicolumn{2}{|c|}{ Placebo supplement } \\
\hline Sodium, g/kg supplement & \multicolumn{2}{|l|}{63.9} & \multicolumn{2}{|l|}{0.86} \\
\hline Butyric acid, g/kg supplement & \multicolumn{2}{|l|}{238} & \multicolumn{2}{|l|}{$<0.1$} \\
\hline \multirow[t]{2}{*}{ Mean } & \multicolumn{2}{|c|}{ Butyrate } & \multicolumn{2}{|c|}{ Placebo } \\
\hline & d1 & $\mathrm{d} 20$ & d1 & $d 20$ \\
\hline Roughage intake (kg) & 6.9 & 6.9 & 6.9 & 6.9 \\
\hline Concentrate + supplement intake $(\mathrm{kg})^{c}$ & 5.8 & 5.8 & 5.9 & 5.9 \\
\hline BW (kg) & 559 & 579 & 571 & 586 \\
\hline Fecal pH & 6.97 & 6.67 & 6.88 & 6.62 \\
\hline Fecal consistency score ${ }^{d}$ & 3 & 3 & 3 & 3 \\
\hline
\end{tabular}

a Analyzed by wet chemistry

${ }^{b}$ Ingredient composition of the concentrate (Cavalor Mash \& Mix ${ }^{c}$ ): flaked barley, wheat bran, linseed, oats, expanded barley, expanded corn, cane molasses, toasted soybeans, horse bean flakes, carrot pieces, calcium carbonate, leek, sodium chloride, soybean meal, fructo oligosaccharides, sunflower meal, palm kernel expeller

${ }^{c}$ Concentrate and supplement provided together (mean values $5.6 \mathrm{~kg}$ concentrate $+229 \mathrm{~g}$ supplement in butyrate-fed group and $5.7 \mathrm{~kg}$ concentrate $+230 \mathrm{~g}$ supplement in placebo-fed group)

${ }^{d}$ Fecal consistency score (1, watery feces, 2, decreased consistency, 3, ideal, 4: hard, 5: constipation) 
Table 2 Longitudinal analysis of feed intake, bwt, fecal pH and fecal consistency

\begin{tabular}{|c|c|c|c|}
\hline Coëfficient & value & SD & $P$-value \\
\hline \multicolumn{4}{|c|}{ Concentrate + supplement intake $(\mathrm{kg})^{\mathrm{a}}$} \\
\hline Day & 0.000 & 0.040 & 0.991 \\
\hline Treatment & -0.171 & 0.855 & 0.841 \\
\hline Day $\mathrm{x}$ treatment & 0.001 & 0.063 & 0.990 \\
\hline \multicolumn{4}{|l|}{ Roughage intake (kg) } \\
\hline Day & 0.000 & 0.015 & 0.991 \\
\hline Treatment & -0.003 & 0.320 & 0.992 \\
\hline Day $x$ treatment & 0.000 & 0.024 & 0.990 \\
\hline \multicolumn{4}{|c|}{ Total feed intake ( $\mathrm{kg}$ roughage + concentrate + supplement) } \\
\hline Day & -0.001 & 0.054 & 0.990 \\
\hline Treatment & -0.175 & 1.157 & 0.880 \\
\hline Day $\mathrm{x}$ treatment & 0.001 & 0.085 & 0.990 \\
\hline \multicolumn{4}{|l|}{ Bodyweight (kg) } \\
\hline Day & 0.773 & 0.170 & $<0.001$ \\
\hline Treatment & -17.680 & 28.895 & 0.542 \\
\hline Day $\mathrm{x}$ treatment & 0.331 & 0.236 & 0.164 \\
\hline \multicolumn{4}{|l|}{ Fecal pH } \\
\hline Day & -0.013 & 0.005 & 0.005 \\
\hline Treatment & 0.007 & 0.185 & 0.970 \\
\hline Day $x$ treatment & -0.005 & 0.006 & 0.423 \\
\hline \multicolumn{4}{|c|}{ Fecal consistency ( $1-5$ scale) } \\
\hline Day & -0.007 & 0.006 & 0.261 \\
\hline Treatment & 0.113 & 0.192 & 0.560 \\
\hline Day $x$ treatment & -0.008 & 0.008 & 0.312 \\
\hline
\end{tabular}

${ }^{a}$ Interpretation of longitudinal analysis: Horses in the placebo group ate on average $5.9 \mathrm{~kg}$ concentrate mixed with placebo supplement a day over the course of the study. Horses fed the butyrate supplement ate $171 \mathrm{~g}$ less on average, but this was not significantly different $(P=0.841)$

dietary treatments in regard to fecal pH $(P=0.423)$. There was no significant effect of time nor treatment on fecal consistency throughout the study $(P=0.261$ and $P=0.312$, respectively).

\section{Intestinal $\mathrm{pH}$ at slaughter}

A period effect was found for CAE $\mathrm{pH}(P=0.047)$ and LVC pH $(P=0.001)$. There was no effect of treatment for intestinal $\mathrm{pH}$ at all locations sampled (Table 3).

\section{Gut histology - intestinal villus length, crypt depth and villus length/crypt depth ratio}

There was no effect of treatment regarding villus length nor villus length/ crypt depth ratio in all segments of the small intestine (data not shown). Horses on the butyrate supplemented diet had significantly lower crypt depths in the RDC compared to placebo-fed horses $(P<0.001)$ (Table 3). For this parameter, a sex- $(P<0.001)$ and a treatment $\mathrm{x}$ period effect was found $(P=0.002)$. A closer look at the data revealed a significant treatment effect in the first period (Mean diet $\mathrm{B}=360 \mu \mathrm{m} \pm 24$, Mean diet $P=559 \mu \mathrm{m} \pm 52, P<0.001$ ) but not in the second (Mean $\operatorname{diet} \mathrm{B}=439 \mu \mathrm{m} \pm 121$, Mean $\operatorname{diet} P=463 \mu \mathrm{m} \pm 90, P=$ $0.821)$.

\section{Gut immunohistochemistry - area \% of CD3 and CD20+ cells and KI67+ cell count}

A significant period effect was found for the expression of CD3 positive cells in the duodenum and ileum $(P=$ 0.010 and $P=0.036$, respectively), whereas for the expression of CD20 positive cells, the period effect was only significant in the duodenum samples $(P=0.004)$. No treatment effect was found for intestinal expression of CD3 or CD20 positive cells in any segment of the gastro-intestinal tract. Expression of KI67 positive cells was not significantly different between treatments in the right dorsal colon crypts (Table 3 ).

\section{Discussion}

A significant rise in body weight over the course of the study was detected in all horses as they were fed above maintenance energy requirements due to the formulated low fiber - high starch diet. The decrease in fecal $\mathrm{pH}$ in both butyrate and placebo supplemented groups throughout the supplementation period is likely due to the fact that the diets were rich in readily-fermentable starch. When this rapidly fermentable carbohydrate arrives in the hindgut, it favours the growth of bacteria that generate lactate, thereby leading to acidification of gut content and hence of feces [2].

The treatment $\mathrm{x}$ period interaction $(P=0.002)$ observed for the crypt depth in the RDC is difficult to explain. A decrease in the nutritive value of the forage due to storage [14] (the same forage batch was offered in the two experimental periods) could be a basis for this interaction. The reduction in RDC crypt depth in horses on the butyrate supplemented diet $(P<0.001)$ contradicts previous findings in other species, as butyrate supplementation is generally associated with an increase in crypt depth [6]. In fact, short-chain fatty acids are known to stimulate epithelial cell proliferation and differentiation, thereby improving healthy tissue turnover [15]. This indicates that findings in poultry, calves and piglets may not be translated directly to the equine species, as this specific hindgut fermenter's gastrointestinal tract does not resemble that of the other species. Further investigation into the number of KI67+ cells in the crypts of the right dorsal colon segment in the current study did not reveal any significant differences between placebo and butyrate supplemented horses $(P=0.650)$, indicating the reduction in crypt depths from butyrate-fed horses could not be explained by a 
Table $3 \mathrm{pH}$, gut histology and immunohistochemistry parameters at different intestinal levels

\begin{tabular}{|c|c|c|c|c|c|c|c|c|c|}
\hline & \multicolumn{2}{|c|}{ Butyrate } & \multicolumn{2}{|c|}{ Placebo } & \multicolumn{5}{|l|}{$P$ - value } \\
\hline & Mean & SD & Mean & SD & Treatment & Period & Age & Sex & Treatment $x$ Period \\
\hline \multicolumn{10}{|l|}{$\mathrm{pH}$} \\
\hline $\mathrm{D}$ & 5.96 & 0.90 & 6.39 & 0.28 & 0.119 & 0.308 & 0.36 & 0.149 & 0.053 \\
\hline J & 7.20 & 0.52 & 7.46 & 0.21 & 0.166 & 0.442 & 0.385 & 0.803 & 0.225 \\
\hline । & 7.58 & 0.22 & 7.49 & 0.25 & 0.110 & 0.143 & 0.66 & 0.418 & 0.061 \\
\hline CAE & 6.74 & 0.15 & 6.67 & 0.14 & 0.820 & 0.047 & 0.746 & 0.961 & 0.768 \\
\hline LVC & 6.61 & 0.20 & 6.64 & 0.24 & 0.697 & 0.001 & 0.174 & 0.966 & 0.467 \\
\hline $\mathrm{RDC}$ & 6.56 & 0.24 & 6.55 & 0.10 & 0.375 & 0.165 & 0.142 & 0.852 & 0.583 \\
\hline \multicolumn{10}{|c|}{ Crypt depth $(\mu \mathrm{m})$} \\
\hline CAE & 262 & 33 & 262 & 34 & 0.143 & 0.195 & 0.822 & 0.916 & 0.118 \\
\hline LVC & 318 & 42 & 320 & 41 & 0.262 & 0.662 & 0.731 & 0.488 & 0.251 \\
\hline $\mathrm{RDC}$ & 399 & 94 & 518 & 84 & $<0.001$ & 0.314 & 0.798 & $<0.001$ & 0.002 \\
\hline \multicolumn{10}{|c|}{ Area $\%$ of CD3 positive cells } \\
\hline $\mathrm{D}$ & 10.096 & 5.131 & 6.193 & 4.535 & 0.745 & 0.010 & 0.802 & 0.127 & 0.192 \\
\hline J & 8.306 & 6.108 & 12.367 & 7.903 & 0.241 & 0.051 & 0.253 & 0.503 & 0.282 \\
\hline I & 9.964 & 6.782 & 14.451 & 10.616 & 0.258 & 0.036 & 0.313 & 0.733 & 0.283 \\
\hline CAE & 16.562 & 10.081 & 16.945 & 9.767 & 0.482 & 0.151 & 0.924 & 0.682 & 0.433 \\
\hline LVC & 11.585 & 8.596 & 12.441 & 4.212 & 0.301 & 0.407 & 0.293 & 0.598 & 0.407 \\
\hline $\mathrm{RDC}$ & 11.126 & 7.560 & 14.240 & 6.977 & 0.207 & 0.173 & 0.398 & 0.769 & 0.254 \\
\hline \multicolumn{10}{|c|}{ Area $\%$ of CD20 positive cells } \\
\hline $\mathrm{D}$ & 6.571 & 7.349 & 5.519 & 4.850 & 0.232 & 0.004 & 0.235 & 0.076 & 0.085 \\
\hline J & 3.798 & 4.169 & 2.279 & 1.585 & 0.241 & 0.051 & 0.253 & 0.503 & 0.282 \\
\hline 1 & 9.428 & 11.087 & 3.143 & 2.409 & 0.714 & 0.529 & 0.761 & 0.021 & 0.840 \\
\hline CAE & 2.427 & 2.981 & 2.720 & 2.110 & 0.759 & 0.159 & 0.505 & 0.079 & 0.704 \\
\hline LVC & 3.186 & 3.127 & 2.452 & 2.854 & 0.153 & 0.068 & 0.008 & 0.032 & 0.034 \\
\hline $\mathrm{RDC}$ & 2.950 & 3.022 & 3.240 & 2.448 & 0.940 & 0.324 & 0.510 & 0.785 & 0.805 \\
\hline \multicolumn{10}{|c|}{ Number of KI67 positive cells per crypt } \\
\hline $\mathrm{RDC}$ & 25 & 10 & 32 & 12 & 0.650 & 0.984 & 0.687 & 0.632 & 0.972 \\
\hline
\end{tabular}

$D$ duodenum, $J$ jejunum, I ileum, CAE cecum, LVC left ventral colon, $R D C$ right dorsal colon

significant difference in cellular proliferation. However, increased crypt cell proliferation rate is not the only cause of an increase in crypt depth. Deeper crypts can be associated with decreased crypt cell apoptosis rate, cell hypertrophy, or a combination of these factors as well [16]. A similar reduction in crypt depth (although only a numerical difference) was reported at the level of the caecum, when supplementing $0.5 \mathrm{~g}$ sodium butyrate $/ \mathrm{kg}$ diet to growing rabbits (also hindgut fermenters) [17]. However, crypt depths in the previous study increased numerically (but remained similar to when a control diet was fed) when the dosage of butyrate was increased to 1.0 and $2.0 \mathrm{~g} / \mathrm{kg}$ diet compared to supplementation with $0.5 \mathrm{~g}$ sodium butyrate $/ \mathrm{kg}$ diet. The amount of butyrate supplemented in the current study $(0.4 \mathrm{~g} / \mathrm{kg} \mathrm{BW}$ or about $18 \mathrm{~g} / \mathrm{kg}$ diet $)$ was based on the study of Glinksy et al. [18], and provided a supplemental $20 \%$ of the estimated normal cecal butyric acid production rate. Dosage of butyrate supplementation likely plays an important role, and could explain the reduction in RDC crypt depth in our study.

With regard to the anti-inflammatory features of butyrate $[9,10]$, significant differences for the expression of CD3 and CD20 cells between the butyrate supplemented and the control horses could be expected. However, the expression of intestinal CD3 cells was not significantly affected by treatment in any of the segments of the gut studied, nor was this the case for the CD20 positive cell population.

A detailed investigation regarding the sodium butyrate release from the micro-capsules would have been valuable. Ideally, the micro-encapsulated sodium butyrate supplement would be released gradually in the large 
intestine. Indeed, coating particles were found upon visual inspection throughout all digestive tract segments of the horses. However, this does not necessarily indicate that the release of butyric acid happened gradually, since the degradation of coating could take longer than the absorption of butyrate. Considering the (mean) retention time of a typical horse diet [19], in combination with an in-house performed in-vitro release test of the supplement (unpublished observations) and the reported availability in other animal species [20], it seems likely that the butyric acid coated supplement would in fact be released gradually in the large intestine. However, it cannot be excluded that the supplement was not, or only partly, released in the large intestine.

The diet used in the current study was formulated to induce a certain amount of starch overflow into the large intestine by providing $2.5 \mathrm{~g}$ sugar and starch $/ \mathrm{kg} \mathrm{BW} / \mathrm{meal}$ (1.6 g starch $/ \mathrm{kg} \mathrm{BW/meal).} \mathrm{It} \mathrm{has} \mathrm{been} \mathrm{demonstrated} \mathrm{that}$ starch fed in excess of $2 \mathrm{~g} / \mathrm{kg} \mathrm{BW} /$ meal may result in potentially harmful quantities of starch reaching the hindgut in horses [3]. In order to prevent carbohydrate-overload induced hindgut disturbances (acidosis, diarrhea, colic) and associated problems (weight loss, laminitis), the authors chose not to formulate a diet containing a sugar and starch content that was extremely high. The purpose of the diet formulated in the present study was to induce subclinical disturbances, but to avoid clinical presentation of hindgut acidosis in the horses. It is however possible that our model did not induce enough acidification and inflammation in the hindgut of the horses, failing to demonstrate the beneficial effects of butyrate supplementation in subclinical gut inflammatory conditions. Furthermore, as this study was performed in slaughter horses, a crossover design was not possible and could be identified as a weakness in the current study. Further studies should focus on horses suffering from large intestinal disease (e.g. right dorsal colitis, carbohydrate overload-induced diarrhea) in order to determine whether supplementing butyric acid can reverse these conditions.

\section{Conclusion}

In conclusion, the present study indicates that supplementation of micro-encapsulated sodium butyrate at 0.4 $\mathrm{g} / \mathrm{kg} \mathrm{BW}$ to healthy adult horses on a low fiber - high starch diet did not significantly influence feed intake, faecal consistency, faecal or intestinal $\mathrm{pH}$, villus length, crypt depth (with the exception of a decrease found in the crypts of the RDC) or intestinal expression of CD3, CD20 and KI67 (RDC) positive cells.

\section{Methods}

\section{Animals and diet}

Fourteen adult warmblood horses (Keros nv, Zonnebeke, Belgium), destined for slaughter, were included in the study and were allocated to one of two groups ensuring uniform distribution between groups of age, sex, body weight (BW) and body condition score (BCS) [21]. Each group contained six intact females and one gelding with a mean age of $10 \pm 5.2$ and $13 \pm 3.1$ years, a mean body weight of $571 \pm 49.1$ and $559 \pm 74.5 \mathrm{~kg}$, and a mean BCS of $4 / 9 \pm 1.1$ and $4 / 9 \pm 1.0$, for the placebo and butyrate supplemented group, respectively. There was no statistical power analysis performed to demonstrate that the quantity of animals used in the study would correspond with the quantity that is statistically required to obtain scientifically relevant results. As this is the first study examining the effect of butyrate supplementation in horses, the standard deviation for the parameters to be examined in horses and the magnitude of the expected effect was unknown at the time. A thorough clinical examination was performed in all horses prior to the study demonstrating all animals were healthy. This examination included a dental check-up, blood- and fecal analysis. None of the horses had a history of gastro-intestinal disorders. Prior to the study, all horses were dewormed using an oral gel preparation containing $200 \mu \mathrm{g}$ ivermectine and $1.5 \mathrm{mg}$ praziquantel $/ \mathrm{kg}$ BW (Equest pramox, Fort Dodge Animal Health Benelux B.V., Weesp, the Netherlands). The horses were individually housed in stables $(3 \times 5 \mathrm{~m})$ with wood shavings as bedding. They were allowed access to a sand paddock for a few hours three times a week. All horses were fed a low fiber - high starch diet designed to induce subsequent starch overflow to the large intestine, thereby aiming to create a mild challenge for large intestinal health. This diet consisted of haylage (given at $1 \%$ of ideal BW on DM basis) and a mash concentrate (Cavalor Mash and Mix, Cavalor, Belgium), and provided $2.5 \mathrm{~g}$ sugar and starch $/ \mathrm{kg}$ BW per meal (Table 1). Horses were consequently fed well above NRC daily maintenance energy requirements [22]. The diet met NRC [22] vitamin and mineral requirements and was divided into two equal meals given at 0800 and $1700 \mathrm{~h}$. Water remained available at all times.

\section{Experimental design}

The experimental protocol was approved by the Ethical Committee of the Faculty of Veterinary Medicine, Ghent University, Belgium (EC 2014/103) and was in accordance with national and institutional guidelines for the care and use of animals. The experiment was performed in two separate periods. The first group of seven horses was included in the study in November, with three horses given a micro-encapsulated sodium butyrate (Excential Butycoat ${ }^{\circ}$, Orffa, Werkendam, the Netherlands) supplemented diet (diet B), and four horses given a placebo (containing only coating material) supplemented diet $(\operatorname{diet} \mathrm{P})$, both supplemented at $0.4 \mathrm{~g} / \mathrm{kg} \mathrm{BW}$. The second 
experimental period took place in April of the following year, with four horses receiving the butyrate supplemented diet and three horses receiving the placebo supplement. All horses were housed at the same facility and accustomed to the same diet before the start of the study. One week prior to the study all horses were gradually transitioned to the new diet, after which the diets were supplemented with either butyrate or placebo and were fed for 20 consecutive days. The supplement was mixed homogeneously with the concentrate mash, so that concentrate consumption would intentionally lead to supplement intake. A pilot study testing palatability was performed in ponies to ensure voluntary intake of the supplement mixed in a concentrate. Over the course of the present study, feed intake was measured daily along with weekly monitoring of $\mathrm{BW}$, fecal $\mathrm{pH}$ and fecal consistency score (1: watery feces, 2: decreased consistency, 3: ideal, 4: hard, 5: constipation). A measuring tape recording girth circumference and body length allowed monitoring of body weight, which was estimated using the equation developed by Carroll and Huntington [23]:

$$
\begin{aligned}
\text { bodyweight }(\mathrm{kg})= & \text { girth }(\mathrm{cm})^{2} \\
& \times \text { length }(\mathrm{cm}) / 11,877
\end{aligned}
$$

After the 20-day period of supplementation, all horses were slaughtered. A penetrating captive bolt gun was used to render the animals unconscious, with exsanguination conducted immediately afterwards to ensure death.
Gut content and tissue samples were collected within 30 min post-exsanguination at six different intestinal locations: duodenum (D), jejunum (J), ileum (I), cecum (CAE), left ventral colon (LVC) and right dorsal colon (RDC).

\section{Assay procedures}

At each of the intestinal locations, gut content $\mathrm{pH}$ was measured in duplicate immediately following collection using a portable $\mathrm{pH}$ meter (Hanna Instruments, Temse, Belgium). Gut tissue samples $(2 \times 2 \mathrm{~cm})$ were initially preserved in formaldehyde and further processed after $24 \mathrm{~h}$. After dehydration of the formalin-fixed samples in xylene, the tissue blocks were trimmed for embedding in paraffin, taking care to orientate the tissue in such a way that the full length of crypts and villi would be visible in the tissue sections. Sections of $4 \mathrm{~mm}$ thickness were cut with a Microm microtome (Prosan, Merelbeke, Belgium) and mounted on glass slides. After deparaffination in xylene ( 2 times, $5 \mathrm{~min}$ ), the tissue sections were rehydrated in isopropylene (5 $\mathrm{min}), 95 \%$ ethanol (5 $\mathrm{min}$ ) and 50\% ethanol (5 min). Sections were stained with haematoxylin and eosin (H\&E) (Fig. 1). Immunohistochemical staining for CD3, CD20 and KI67 positive (for the RDC sections) cells was performed utilising different sections obtained as previously described. CD3 cell staining is characterized as a immunohistochemical marker for T-cells in tissue sections and CD20 staining (Fig. 2) as a marker for B cells [24]. Staining of KI67 positive cells (Fig. 3) allows

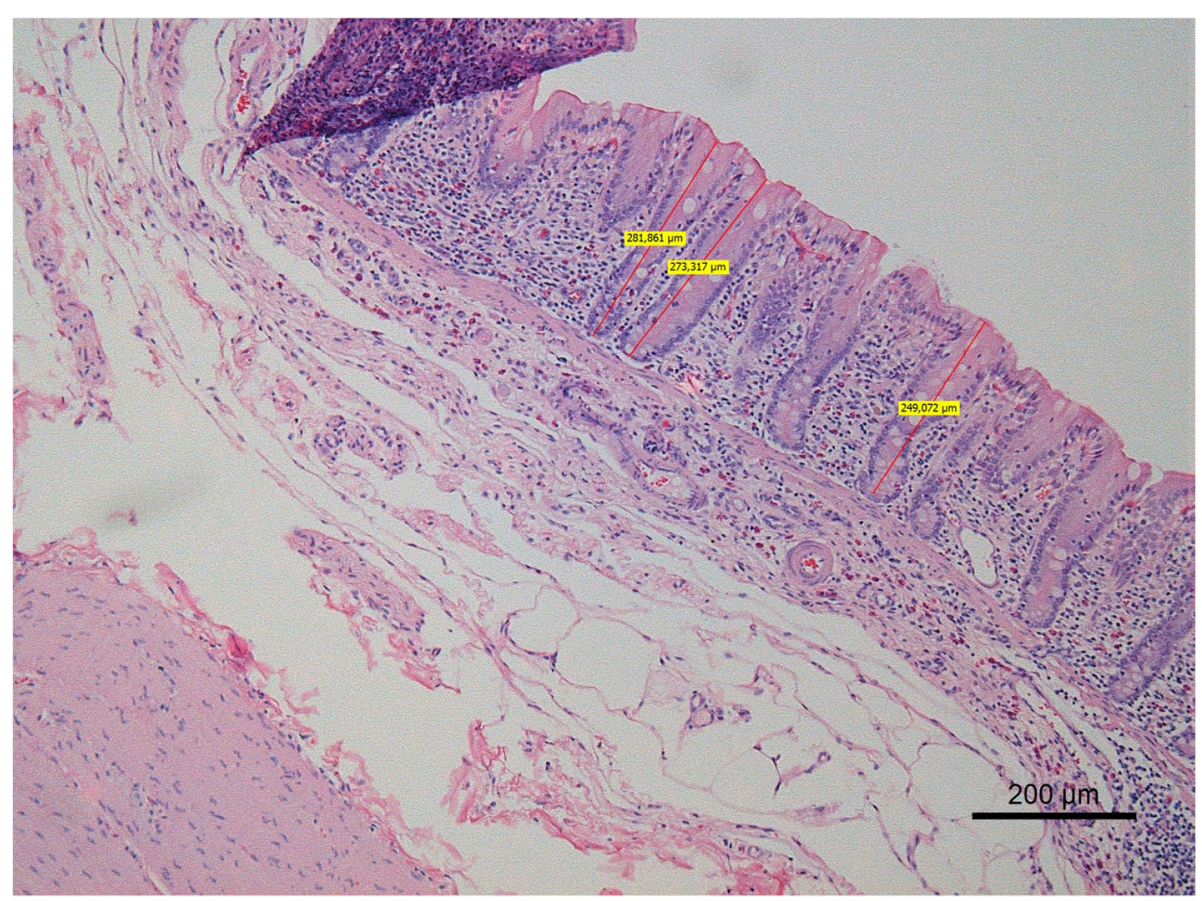

Fig. $1 \mathrm{HE}$ staining of the equine cecum, demonstrating crypt depth measurements ( $\mu \mathrm{m})$ 


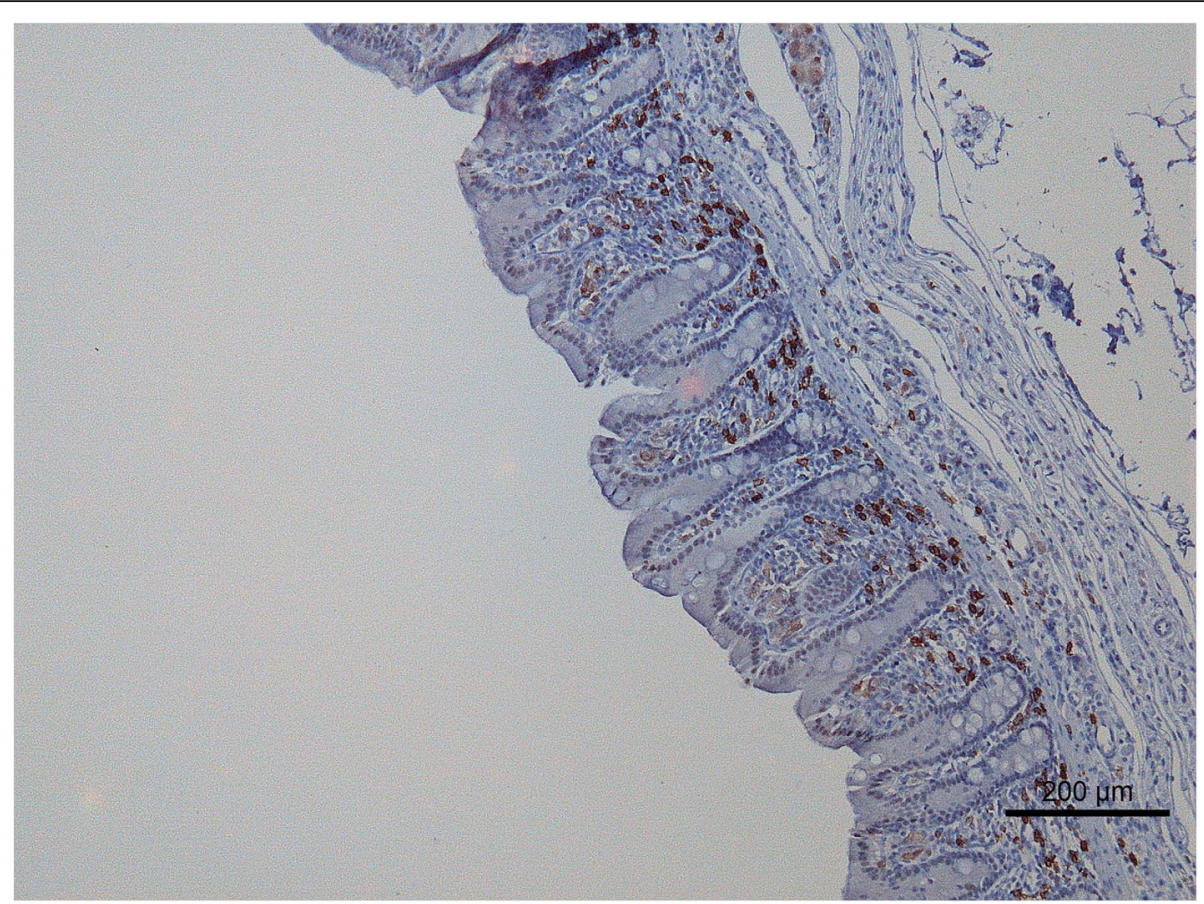

Fig. 2 Photomicrograph of CD20 staining of the equine cecum (CD20 positive cells are brown colored)

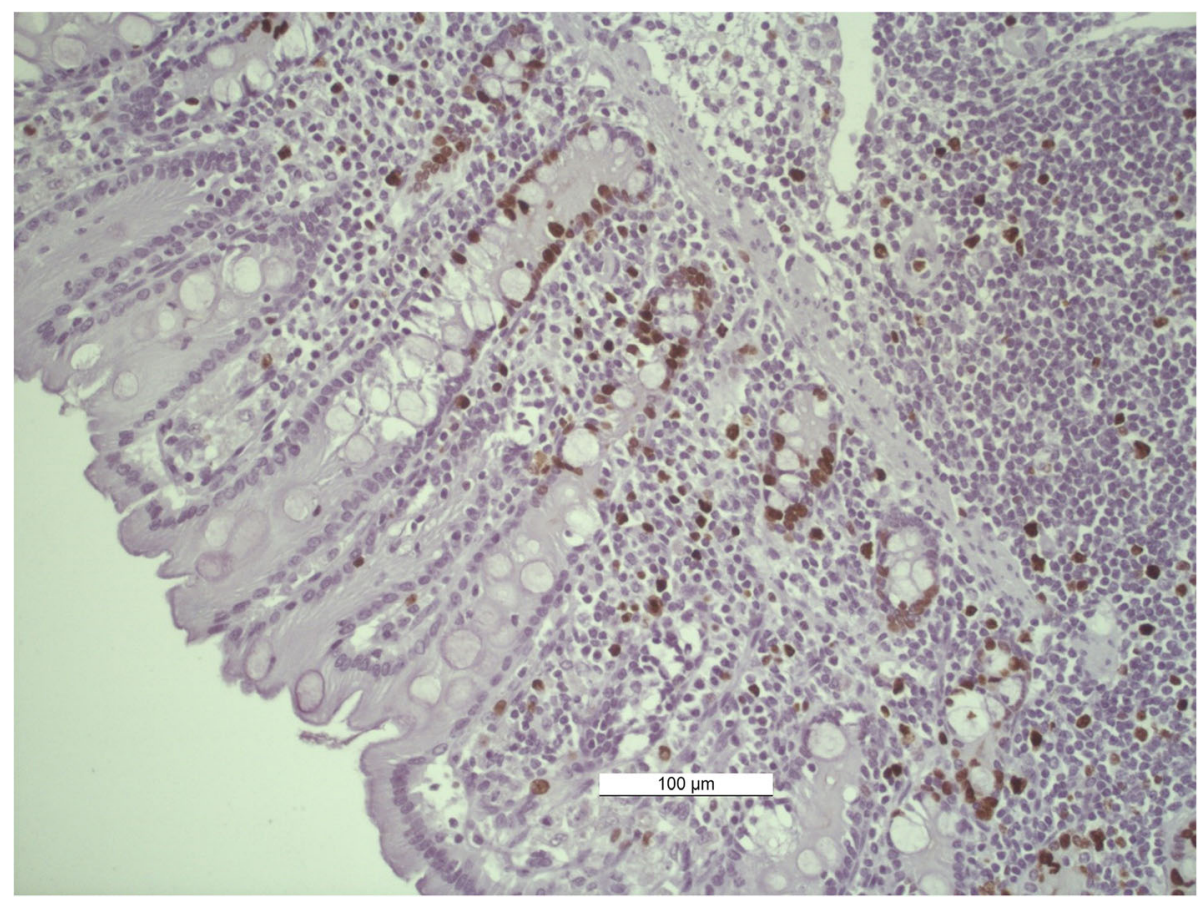

Fig. 3 Photomicrograph of K167 staining of the equine right dorsal colon (KI67+ cells are brown colored) 
evaluation of proliferating cells [25]. Sections were examined using a DM2000 microscope and a Leica Camera DFC320 (Leica Microsystems Ltd., Wetzlar, Germany) coupled to a computer-based image analysis system LAS $^{\circ}$ (v.3.8., Leica Microsystems Ltd). Villus length and crypt depth were measured on the H\&E stained sections, measuring three villi and three crypts per sample. CD3 and CD20 cell density in the lamina propria was measured using "area percentage" from three locations per sample. KI67 positive cells were counted individually in nine crypts per RDC sample.

\section{Statistical methods}

Prior to further analysis, normality of distribution was confirmed for all data using the Kolmogorov-Smirnov and Shapiro-Wilk tests and equality of data variability was checked with Levene's test. For these tests, Superior Performing Software Systems version 23 (SPSS Inc., Chicago, Illinois, USA) was used. To evaluate the effect of butyrate supplementation on feed intake, BW, fecal $\mathrm{pH}$ and fecal consistency, a longitudinal analysis was performed using R-studio (version 3.2.5, 16 April 2016) and the packages 'gplot', 'lattice', 'ggplot2' and 'nlme'. All other data were analysed in a general additive mixed model with treatment (butyrate versus placebo), period, age, sex and treatment $\mathrm{x}$ period as fixed effects and horse as random effect. These analyses were conducted using R-studio (version 3.2.5, 16 April 2016) and package 'gamm4'. P-values below 0.05 were set as statistically significant and a $P$ value between 0.1 and 0.05 was defined as a trend.

\section{Abbreviations}

BCS: Body condition score; BW: Body weight; Diet B: Butyrate supplemented diet; Diet P: Placebo supplemented diet; D: Duodenum; I: lleum; J: Jejunum; CAE: Caecum; LVC: Left ventral colon; RDC: Right dorsal colon;

H\&E: Haematoxylin and eosin; DM: Dry matter

\section{Acknowledgements \\ The authors gratefully acknowledge the personnel of Keros nv, Euro Meat Group sa and the Department of Veterinary Pathology of Ghent University, the manuscript drafting assistance of T. Kujawa, the laboratory assistance of A. Keita and the technical assistance of O. Dansen, A. De Cuyper, R. Dejaifve, F. Demeyere, H. Derycke, M. Jacobs, A. Khadem, J. Pauwels, W. Van Caeneghem, V. Vandendriessche, M. Verschuur and J. Xu.}

\section{Authors' contributions}

WW contributed to the study design and execution, sample collection, sample analysis and was responsible for interpretation of analysed data, and preparation of the manuscript. DVD was responsible for the study design, and contributed to data collection and analysis, data interpretation and manuscript preparation. PRP contributed to the study design, data collection, data interpretation and manuscript preparation. RD contributed to the study design, sample analysis, data interpretation and manuscript preparation. LV contributed to the study execution and manuscript preparation. ML performed the statistical analysis and contributed to data interpretation and manuscript preparation. MH (supervisor of WW) contributed to the study design, data analysis and interpretation and preparation of the manuscript. All authors read and approved the final manuscript.

\section{Funding}

This study was funded by Cavalor, Drongen, Belgium and Orffa, Werkendam, the Netherlands. Co-author D.A. van Doorn was hired in his role as an equine nutrition consultant by Cavalor, Drongen, Belgium to co-ordinate the execution of the project. D.A. van Doorn was responsible for the study design, and contributed to data collection and analysis, data interpretation and manuscript preparation. Co-author P. M. Rovers-Paap, employed with Orffa, contributed to the study design, data collection, data interpretation and manuscript preparation.

\section{Availability of data and materials}

The datasets used and/or analysed during the current study are available from the corresponding author on reasonable request.

\section{Ethics approval and consent to participate}

The experimental protocol was approved by the Ethical Committee of the Faculty of Veterinary Medicine, Ghent University, Belgium (EC 2014/103) and was in accordance with institutional and national guidelines for the care and use of animals. Horses were owned by Keros nv, Zonnebeke, Belgium. Written informed consent to use the animals in the study was obtained from the owner of the animals.

\section{Consent for publication}

Not Applicable.

\section{Competing interests}

Co-author P. M. Rovers-Paap is employed with Orffa, whose product is used in the current study. All other authors declare no competing interests.

\section{Author details}

'Laboratory of Animal Nutrition, Department of Nutrition, Genetics and Ethology, Faculty of Veterinary Medicine, Ghent University, Heidestraat 19, 9820 Merelbeke, Belgium. ${ }^{2}$ Department of Equine Sciences and Department of Farm Animal Health, Faculty of Veterinary Medicine, Utrecht University, P.O. Box 80.151, 3508 TD Utrecht, the Netherlands. ${ }^{3}$ Equivado, Equine Nutrition Consultancy, Marnixlaan 80, 3552 HG Utrecht, the Netherlands. ${ }^{4}$ Orffa, Vierlinghstraat 51, 4251LC Werkendam, the Netherlands. ${ }^{5}$ Department of Pathology, Bacteriology and Avian Diseases, Faculty of Veterinary Medicine, Ghent University, Salisburylaan 133, 9820 Merelbeke, Belgium. ${ }^{6}$ Department of Surgery and Anesthesiology of Domestic Animals, Faculty of Veterinary Medicine, Ghent University, Salisburylaan 133, 9820 Merelbeke, Belgium. ${ }^{7}$ Present address: Flanders Research Institute for Agriculture, Fisheries and Food, Scheldeweg 68, 9090 Melle, Belgium.

Received: 19 April 2018 Accepted: 5 April 2020

Published online: 28 April 2020

\section{References}

1. Marshall D. Equine colic. Vet Rec. 2013;172:292.

2. Durham AE. Intestinal disease. In: Geor R, Coenen M, Harris P, editors. Equine applied and clinical nutrition: health, welfare and performance. Philadelphia: Elsevier Health Sciences; 2013. p. 568-81.

3. Geor RJ, Harris PA. How to minimize gastrointestinal disease associated with carbohydrate nutrition in horses. In: Proceedings of the 53rd Annual Convention of the American Association of Equine Practitioners. Orlando, Florida; 2007. p. 178-85.

4. Meschter CL, Tyler DE, White NA, Moore J. Histologic findings in the gastrointestinal tract of horses with colic. Am J Vet Res. 1986;47:598-606.

5. White NA, Moore JN, Trim CM. Mucosal alterations in experimentally induced small intestinal strangulation obstruction in ponies. Am J Vet Res. 1980;41(2):193-8.

6. Guilloteau P, Martin L, Eeckhaut V, Ducatelle R, Zabielski R, Van Immerseel F. From the gut to the peripheral tissues: the multiple effects of butyrate. Nutr Res Rev. 2010;23:366-84

7. Kripke SA, Fox AD, Berman JM, Settle RG, Rombeau JL. Stimulation of intestinal mucosal growth with intracolonic infusion of short-chain fatty acids. J Parenter Enter Nutr. 1989;13:109-16.

8. Ziegler T, Evans M, Fernandez-Estivariz C, Jones D. Trophic and cytoprotective nutrition for intestinal adaptation, mucosal repair and barrier function. Annu Rev Nutr. 2003;23:229-61. 
9. Andoh A, Bamba T, Sasaki M. Physiological and anti-inflammatory roles of dietary fiber and butyrate in intestinal functions. J Parenter Enter Nutr. 1999; 23:S70-3.

10. Di Sabatino A, Cazzola P, Ciccocioppo R, Morera R, Biancheri P, Rovedatti L, Cantoro L, Vanoli A, Tinozzi FP, Tinozzi S, Corazza GR. Efficacy of butyrate in the treatment of mild to moderate Crohn's disease. Dig Liver Dis. 2007;1:315.

11. Abrahamse SL, Pool-Zobel BL, Rechkemmer G. Potential of short chain fatty acids to modulate the induction of DNA damage and changes in the intracellular calcium concentration by oxidative stress in isolated rat distal colon cells. Carcin. 1999:20:629-34.

12. Rosignoli P, Fabiani R, De Bartolomeo A, Spinozzi F, Agea E, Pelli MA, Morozzi G. Protective activity of butyrate on hydrogen peroxide induced DNA damage in isolated human colonocytes and HT29 tumour cells. Carcin. 2001:22:1675-80.

13. Mortensen FV, Nielsen H, Mulvany MJ, Hessov I. Short chain fatty acids dilate isolated human colonic resistance arteries. Gut. 1990;31:1391-4.

14. Rotz CA, Muck RE. Changes in forage quality during harvest and storage. In: Forage quality, evaluation, and utilization; 1994. p. 828-68.

15. Scheppach W, Bartram HP, Richter F. Role of short-chain fatty acids in the prevention of colorectal cancer. Eur J Cancer. 1995;31:1077-80.

16. Abimosleh SM, Lindsay RJ, Butler RN, Cummins AG, Howarth GS. Emu oil increases colonic crypt depth in a rat model of ulcerative colitis. Dig Dis Sci. 2012;57:887-96.

17. Carraro L, Xiccato G, Trocino A, Radaelli G. Dietary supplementation of butyrate in growing rabbits. Ital J Anim Sci. 2005:4(S2):538-40

18. Glinsky MJ, Smith RM, Spires HR, Davis CL. Measurement of volatile fatty acid production rates in the cecum of the pony. J Anim Sci. 1976;42:146570.

19. Van Weyenberg S, Sales J, Janssens GPJ. Passage rate of digesta through the equine gastrointestinal tract: a review. Livest Sci. 2006;99(1):3-12.

20. Hamer HM, Jonkers DMAE, Venema K, Vanhoutvin SALW, Troost FJ, Brummer RJ. The role of butyrate on colonic function. Alim Pharmacol Ther. 2008;27(2):104-19.

21. Henneke DR, Potter GD, Kreider JL, Yeates BF. Relationship between condition score, physical measurements and body fat percentage in mares. Eq Vet J. 1983;15:371-2.

22. National Research Council (NRC). Nutrient requirements of horses. 6th revised ed. Washington, DC: National Academy Press; 2007.

23. Carroll CL, Huntington PJ. Body condition scoring and weight estimation of horses. Eq Vet J. 1988;20:41-5.

24. Dabbs DJ. Diagnostic immunohistochemistry, theranostic and genomic applications. 4th ed. Philadelphia: Elsevier Health Sciences; 2014.

25. Bryant RJ, Banks PM, O'malley DP. Ki67 staining pattern as a diagnostic tool in the evaluation of lymphoproliferative disorders. Histopath. 2006;48:50515.

\section{Publisher's Note}

Springer Nature remains neutral with regard to jurisdictional claims in published maps and institutional affiliations.

Ready to submit your research? Choose BMC and benefit from:

- fast, convenient online submission

- thorough peer review by experienced researchers in your field

- rapid publication on acceptance

- support for research data, including large and complex data types

- gold Open Access which fosters wider collaboration and increased citations

- maximum visibility for your research: over $100 \mathrm{M}$ website views per year

At $\mathrm{BMC}$, research is always in progress.

Learn more biomedcentral.com/submissions 